\title{
UNIT COMMITMENT USING PARTICLE SWARM OPTIMIZATION TECHNIQUE
}

\author{
M. A. Bishr \\ Department of Electrical Engineering, Faculty of Engineering, Shebin El-Kom \\ Minoufiya University, Egypt
}

\begin{abstract}
This paper proposes an application of the Particle Swarm Optimization technique to unit commitment (UC) problem. In the proposed technique, the unit commitment is formulated as a nonlinear optimization problem subject to the applicable constraints. A numerical comparison between the results of the proposed technique and that of Dynamic Programming one has been developed. This paper also represents a good contribution to the application of one of the modern heuristic techniques in the power systems engineering area. The proposed solution methodology has been validated and tested using known test system. The results obtained compared favorably with those already available, thus showing the effectiveness and applicability of the Particle Swarm Optimization technique for solving complex power system engineering problems.
\end{abstract}

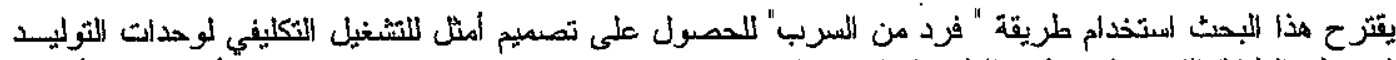

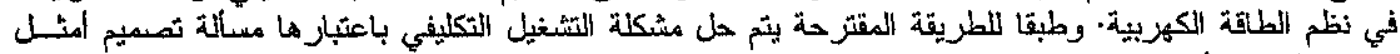

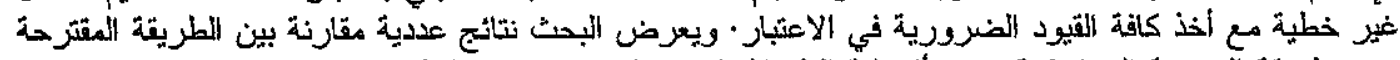

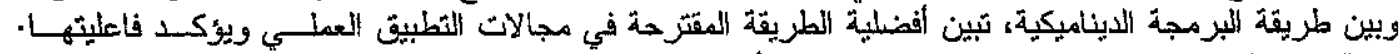

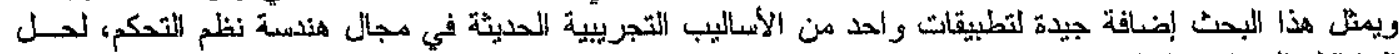
المشاكل المتعلقة بالنظم الكبيرة و المعقدة.

Keywords: Unit Commitment, Particle Swarm, Optimization techniques, Dynamic programming.

\section{INTRODUCTION}

In large-scale power systems, the solution to complex multidimensional problems using classical optimization techniques is very difficult and computationally expensive. Therefore, an increased interest has been devoted to a special class of searching algorithms, namely, heuristic algorithms. Many heuristic algorithms have evolved in the last decades that have facilitated solving optimization problems that were previously very difficult or impossible to solve. These algorithms include, but are not limited to: genetic algorithms [1], evolutionary strategies [2], simulated annealing [3], and particle swarm optimization [4]. These new heuristic algorithms have been combined (or hybridized) among themselves and with knowledge elements, as well as with more traditional approaches, to solve extremely challenging problems. Particle Swarm Optimization (PSO) refers to a relatively new family of algorithms that may be used to find optimal solutions to numerical and qualitative problems. PSO was introduced by Russell Eberhart and James Kennedy in 1995 [5], inspired by the social behavior of bird flocking or fish schooling. It is easily implemented in most programming languages and has proven to be both very fast and effective when applied to a diverse set of optimization problems [6]. The overall objective of this paper is to use this modern heuristic optimization algorithm (PSO) for solving unit commitment problem. This problem could be solved using a classical solution method like Dynamic Programming [7]. Also this paper is aimed at determining the optimal set of generating units to be used during a load cycle, while the operational costs (mainly fuel cost) and transition costs (start-up/shut-down costs) are minimized.

\section{SOLUTION FRAMEWORK}

To achieve the solution for the unit commitment problem using PSO, the following steps are followed:

1) Formulate the unit commitment problem as a mathematical optimization problem subject to the applicable constraints. In this step, the unit commitment problem is overviewed and mathematically formulated (Section 3).

2) Formulate and apply PSO models to the unit commitment through developing and 


\section{A. Bishr "Unit Commitment Using Particle Swarm Optimization Technique"}

implementing the corresponding PSO solution methodologies (Section 4).

3) Use well known approach applied to a simple case study to solve the unit commitment problem is the third step and this is obtained in Section 5 . To validate the proposed method, the results obtained from classical approach are compared with the results that obtained from PSO.

\section{UNIT COMMITMENT}

\subsection{Unit Commitment Overview}

The unit commitment procedure plans for the most economical set of generation units to be available to supply the forecasted load of the system over a future time scope. Although there are many other factors of practical significance that determine when units are scheduled on and off to satisfy the operating needs of the system, economic operation is very important.

For large-scale power systems, the unit commitment problem is very difficult to solve. Actually the most popular approaches used for its solution are Priority. list Schemes, Dynamic Programming and Lagrange Relaxation. References [8-16] present some of the different solution approaches that have been applied to the unit commitment problem. In [17], a classical solution to the unit commitment problem using Dynamic Programming is discussed. The objective of the unit commitment problem is to minimize the costs and to schedule the generation units for each time period in order to satisfy the system load. Only generation units activated in a given period are considered in the economic dispatch.

\subsection{Mathematical Formulation of the Unit Commitment Problem}

In general, unit commitment (UC) is an optimization problem and can be formulated mathematically as follows:

$$
\begin{aligned}
& F_{0}=\operatorname{Min}\left\{\sum_{k=1}^{N_{p}}\left[M_{p} \sum_{i=1}^{N_{b}}\left[c_{a}+c_{11} P_{i k}+c_{z} P_{1, k}^{2}\right]\right]+\right. \\
& \sum_{k=1}^{N-1} \sum_{i=1}^{N}\left[S_{i, k} U_{i, k} \mid U_{i, k}-U_{i, k}+1\right]+ \\
& \left.\sum_{k=1}^{N_{p-1}} \sum_{i=1}^{N_{k}}\left[D_{i, k} U_{i, k}\left|U_{i, k}-U_{i, k}+1\right|\right]\right\}
\end{aligned}
$$

where $F_{0}$ is the objective function of the operational cost and the target is to minimize this function. The terms of the function are defined as follows:

$M_{\mathrm{p}}$ : number of hours per period

$\mathrm{N}_{\mathrm{G}}$ : total number of generation units

$N_{p}$ : total number of periods in 24 hours
$P_{i, k}$ : real power generation unit $i$ during the period $k$

$U_{i, k}: U_{i, k}=1$ if generation unit $i$ is on-line,

$$
: U i, k=0 \text { if generation unit } i \text { is off-line }
$$

$c_{o i}, c_{1 i}$, and $c_{2 i}$ : the generation unit $i$ cost coefficients

$\mathrm{S}_{\mathrm{i}, \mathrm{k}}$ : start-up cost of generation unit $\mathrm{i}$ during the $\mathrm{k}^{\text {th }}$ period

$D_{i, k}$ : shut-down cost of generation unit $i$ during the $\mathrm{k}^{\mathrm{Th}}$ period

This function consists of production costs and transition costs. Transition costs are the costs associated with changing from one combination of generation units to another combination. Start-up and shut-down stages of generation units involve personnel requirements and facility's coordination. Usually fixed costs are assigned to the status change of each generation units. According to the following expression, a cost is introduced if there is a transition from state off to state on for generation unit Ui:

$\sum_{k=1}^{N_{m i 1}} \sum_{j=1}^{N_{i}}\left[S_{i, k} U_{i, k} \mid U_{i, k}-U_{i, k}+1\right]$

Also according to the following expression, a cost is introduced if there is a transition from state on to state off for generation unit Ui:

$\left.\sum_{k=1}^{N_{p-1}} \sum_{i=1}^{N_{G}}\left[D_{i, k} U_{i, k} \mid U_{i, k}-U_{i, k}+1\right]\right]$

The minimum uptime and minimum downtime constraints state that a unit that is running must be up for at least a specified time and a unit that is down must stay down for at least specified time. The minimum uptime constraints arise from physical considerations associated with thermal stress on the units and are designed to prevent equipment fatigue. The minimum downtime constraints, on the other hand, are based on economic considerations intended to prevent excessive maintenance and repair costs due to frequent unit cycling. The following constraints express the premature start-up and shutdown costs:-

$$
\begin{aligned}
& F_{P S T}\left(P_{k}\right)=\sum_{i=1}^{N_{G}} \sum_{m=1}^{M}\left[q_{i, k} U_{i, k-m+1}\left|U_{i, k}-U_{i, k-m, t)}\right|\right] \\
& F_{P S O}\left(P_{k}\right)=\sum_{i=1}^{N_{G}} \sum_{m=1}^{M}\left[q_{i, k} U_{i, k-m}\left|U_{i, k-m}-U_{i, k-m+1}\right|\right]
\end{aligned}
$$

where:

$\mathrm{F}_{\mathrm{PST}}\left(\mathrm{P}_{\mathrm{k}}\right)$ : Overall start-up costs during $\mathrm{k}^{\mathrm{th}}$ period 


\section{A. Bishr "Unit Commitment Using Particle Swarm Optimization Technique"} $\mathrm{F}_{\mathrm{PSD}}\left(\mathrm{P}_{\mathrm{K}}\right)$ : $\begin{aligned} & \text { Overall shut-down costs during } \mathrm{k}^{\text {th }} \\ & \text { period }\end{aligned}$

$q_{i, k} \quad:$ start-up or shut-down costs of the $i^{\text {th }}$ generation unit during the $\mathrm{k}^{\text {th }}$ period

M

: Number of hours the units should stay on or off

There is also another kind of constraints which is known as the power balance constraint. It guarantees that the load demand will be met considering the transmission losses of a power system.

$\sum_{i=1}^{N_{G}}\left[U_{i, k} P_{i, k}\right]-P D_{k}-P L_{k}=0$

where:

$\mathrm{PD}_{\mathrm{k}}$ : load demand during $\mathrm{k}^{\text {th }}$ period

$\mathrm{PL}_{\mathrm{k}}$ : Transmission losses during $\mathrm{k}^{\text {th }}$ period

The minimum and maximum limits of generation units are of concern during the economical dispatch and unit commitment problems. This constraint ensures the safe operation of the system during each period.

$\mathrm{P}_{\mathrm{i}, \mathrm{k}}^{\min } \leq \mathrm{P}_{\mathrm{i}, \mathrm{k}} \leq \mathrm{P}_{\mathrm{i}, \mathrm{k}}^{\max }$

Where: $P_{i, k}^{\min }$ and $P_{i, k}^{\max }$ are the lower and upper generation limits of generation unit $i$ during the $k^{\text {th }}$ period.

The spinning reserve is another type of constraints and it is an important operational requirement in power systems. Spinning reserve equal the total power generation available minus the corresponding load demand and transmission losses. This reserve ensures that there will not be a large drop in system frequency if one or more generation units trip. The spinning reserve is also necessary to ensure that available generating capacity always exceeds load demand by certain amount. Usually the spinning reserve is set equal to the capacity of the largest generation unit in the system or to a given percent of the load demand. The spinning reserve constraint can be expressed as follows:

$\sum_{k=1}^{N_{G}}\left[U_{i, k} P_{1, k}^{\max }\right]-P D_{k}-P L_{k} \geq S R_{k}$

where: $\mathrm{SR}_{\mathbf{k}}$ is the system spinning reserve requirement during the $\mathrm{k}^{\text {th }}$ period.

The last type of constraints is the ramp rate constraints. The ramp rate limits confine the output movement of a generation unit between adjacent periods. Ramp rate arises because the rate of the generation changes must be limited within certain ranges due to the physical restrictions on thermal generation units. It can be expressed as follows:

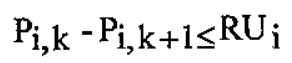

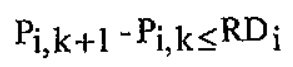

where:

$R U_{i}$ : The ramp-up rate limit of generation unit $\mathrm{i}$.

$R D_{\mathrm{i}}$ : The ramp-down rate limit of generation unit i.

At this point the mathematical formulation of the problem has been derived and the next step is to introduce and implement the PSO technique to solve this problem.

\section{PSO FOR THE UNIT COMMITMENT PROBLEM}

\subsection{PSO Overview}

PSO is considered as an evolutionary computation technique, and is a population based optimization approach. It is motivated from the simulation of social behavior. It updates the population of individuals by applying some 'kinds of operators according to the fitness information obtained from the environment so that the individuals of the population can be expected to move towards better areas of the problem's search space. The system is initialized with a population of random feasible solutions and searches for optimal solution by updating generations. PSO updates the generations using a stochastic operation, it has a velocity update. The population of candidate solutions in PSO technique is moved through the search space updating the positions according to velocity factors.

\subsection{PSO Technique}

PSO was originally developed by a social psychologist (James Kennedy) and an electrical engineer (Russell Eberhart) in 1995 [5,18], and emerged from earlier experiments with algorithms that modeled the flocking behavior seen in many species of birds. Although there were a number of such algorithms getting quite a bit of attention at the time, Kennedy and Eberhart became particularly interested in the models developed by biologist Frank Heppner [19]. Heppner studied birds in flocking behaviors mainly attracted to a roosting area. In simulations, birds would begin by flying around with no particular destination and spontaneously formed flocks until one of the birds flew over the roosting area. Due to the simple rules the birds used to set their directions and velocities, a bird pulling away from the flock in order to land at the roost would result in nearby birds moving towards the roost. Once these birds discovered the roost, they would land 
there, pulling more birds towards it, and so on until the entire flock had landed. Finding a roost is analogous to finding a solution in a field of possible solutions in a solution space. The manner in which a bird who has found the roost, leads its neighbors to move towards it, increases the chances that they will also find it. This is known as the "socio-cognitive view of mind". The "socio-cognitive view of mind" means that a particle learns primarily from the success of its neighbors. Eberhart and Kennedy revised Heppner's methodology [19] so that particles could fly over a solution space and land on the best solution simulating the birds' behavior. Each particle should compare themselves to others and imitate the behavior of others who have achieved a particular objective successfully. Eberhart and Kennedy developed a model that balances the cooperation between particles in the swarm. An appropriate balance between exploration (individuals looking around for a good solution) and exploitation (individuals taking advantage of someone else's success), is a main concern in the Eberhart and Kennedy model. Too little exploration and the particles will all converge to the first good solution found (typically a local solution). Too little exploitation and the particle will take longer to converge (or may not converge at all). In summary, the Eberhart and Kennedy model attempts to find the best compromise between its two main components, individuality and sociality. PSO could be modeled to handle continuous variables or binary variables and its algorithm is explained in [20].

\subsection{Formulation of unit commitment for PSO}

The unit commitment problem searches for the most economic feasible combination of generating units to serve the forecast load of the power system at each period of the load cycle. In the formulation, the statuses of the generation units at each period are the control variables. These control variables are binary variables ( 0 or 1$)$ that represent the generation units' status, on or off. In this approach, there are twenty four control variables for the case study. This case study consists of four generation units and six periods based on four hours per period resulting in a 24 hours load cycle. All control variables are binary variables. The first four parameters of the control variables vector are the status of the four-generation units at the first period. The next four parameters of the control variables vector are the status of the fourgeneration units at the second period and so on. Finally the last four parameters of the control variables vector are the status of the four-generation units at the sixth and final period. All control variables were handled using the PSO model for binary variables. Table 1 shows the structure of each vector of control variables (or particle):
Table 1 Control variables vector or particle for unit commitment problem

\begin{tabular}{|c|c|c|c|c|}
\hline Gen. Units & $\mathrm{PG}_{1}$ & $\mathrm{PG}_{2}$ & $\mathrm{PG}_{3}$ & $\mathrm{PG}_{4}$ \\
\hline 1 & $\mathrm{U}_{1,1}$ & $\mathrm{U}_{2, \mathrm{I}}$ & $\mathrm{U}_{3,1}$ & $\mathrm{U}_{4,1}$ \\
\hline 2 & $\mathrm{U}_{1,2}$ & $\mathrm{U}_{2,2}$ & $\mathrm{U}_{3,2}$ & $\mathrm{U}_{4,2}$ \\
\hline 3 & $\mathrm{U}_{1,3}$ & $\mathrm{U}_{2,3}$ & $\mathrm{U}_{3,3}$ & $\mathrm{U}_{4,3}$ \\
\hline 4 & $\mathrm{U}_{1,4}$ & $\mathrm{U}_{2,4}$ & $\mathrm{U}_{3,4}$ & $\mathrm{U}_{4,4}$ \\
\hline 5 & $\mathrm{U}_{1,5}$ & $\mathrm{U}_{2,5}$ & $\mathrm{U}_{3,5}$ & $\mathrm{U}_{4,5}$ \\
\hline $6^{\circ}$ & $\mathrm{U}_{\mathrm{i}, 6}$ & $\mathrm{U}_{2,6}$ & $\mathrm{U}_{3,6}$ & $\mathrm{U}_{4,6}$ \\
\hline
\end{tabular}

At each iteration, every particle determines a possible set of generation units in service for the total load cycle. The following fitness function was used according to the requirements of case study Figure 1:

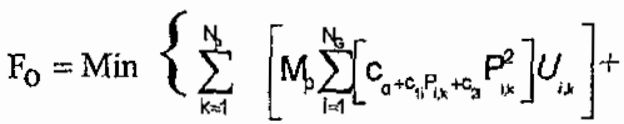

$$
\begin{aligned}
& \sum_{k=1}^{N_{k}=1} \sum_{i=1}^{N_{0}}\left[S_{i, k} U_{i, k}\left|U_{i, k}-U_{i, k}+1\right|\right]+ \\
& \sum_{k=1}^{N_{p-1}} \sum_{i=1}^{N_{G}}\left[D_{i, k} U_{i, k}\left|U_{i, k}-U_{i, k}+1\right|\right]+ \\
& \left.\sum_{k=1}^{N_{p}} A_{P_{k}}\left(\sum_{i=1}^{N_{G}} U_{i, k} P_{i, k}-P D\right)^{2}\right\}
\end{aligned}
$$

Subject to:

$$
\mathrm{P}_{\mathrm{i}, \mathrm{k}}^{\min } \leq \mathrm{P}_{\mathrm{i}, \mathrm{k}} \leq \mathrm{P}_{\mathrm{i}, \mathrm{k}}^{\max }
$$

where:

$\mathrm{A}_{\mathrm{P}_{\mathrm{k}}}:$ Penalty factor associated with the violation in
power balance constraint at $k^{\text {th }}$ period. $\mathrm{N}_{\mathrm{p}}$ : Total number of periods in 24 hours.

The limits of generation constraint is neither penalized nor included in the fitness function. This constraint is handled by the economic dispatch phase. An economic dispatch is run for each particle generated by the PSO approach. A Gradient Based Economic Dispatch was used as part of the approach. PSO approach was focused on the binary part of the formulation. Beside that, power losses, and premature start-up and shut-down costs constraints were not included in the formulation.

As part of the approach, the infeasible combinations were not eliminated. PSO approach was developed in such manner that if the demand at the $\mathrm{k}^{\text {th }}$ period can not be supplied by the available generation, a penalty 


\section{A. Bishr "Unit Commitment Using Particle Swarm Optimization Technique"}

factor (i.e., large weight number) is added to the fitness function. After several trials, the PSO parameters were selected. The inertia weight was set to 0.9 , as recommended in [21]. The constant $c 1$ and $c 2$ were set to 1 . These values were selected based on the results of several trials. The size of the swarm. was 20 particles. As converge criteria, the algorithm stops looking for a solution if the global best solution does not change after 15 consecutives iterations and the iteration have reached $10 \%$ of the maximum number of iterations specified. This maximum number of iterations was set to 100 .

\section{APPLICATIONS}

\subsection{The Case study Description}

In order to test and validate the proposed approach, a case study was used [17]. Figure 1 and Table (2) describe the system load demand and generation unit data. The generation units 1 and 2 are to operate at the first and the final periods of the load cycle where load is $1100 \mathrm{MW}$ according to [17]. Also, both generation units must be considered as "must-run" units during whole cycle. Therefore, both generation units must remain turned on at all periods. The "must-run" units are the generation units that must be continuously operating for operational requirements reasons. The case study [17] assumes a start-up cost of $\$ 3,000$ and a shutdown cost of $\$ 1,500$ for each generation unit. It does not consider the transmission losses and the spinning reserve requirement for the test system, as well as the premature start-up and shut-down costs constraints.

\subsection{Unit Commitment Solution by the Main Classical Approach}

The main classical approach used for solving the problem is Dynamic Programming with a Classical Economic Dispatch [17].

There are only four combinations included in the Dynamic Programming Approach. The other combinations are infeasible due to the fact that generation units 1 and 2 must be kept running as specified. Performing an economic dispatch when load demand is $1600 \mathrm{MW}$ using the combination U1 $=1, \mathrm{U} 2=1, \mathrm{U} 3=1$ and $\mathrm{U} 4=1$ results in a generation schedule of $\mathrm{PG} 1=410 \mathrm{MW}, \mathrm{PG} 2=508$ MW, PG3 $=338 \mathrm{MW}$ and PG4 = $344 \mathrm{MW}$. With these power outputs the total production cost obtained for this combination is $67,258 \$ /$ Period instead of $70,908 \$ /$ Period as documented in [17]. Figure (2) shows the results obtained from Dynamic Programming approach which is a deterministic optimization technique. Table (3) shows the economic dispätch results from the main classical Dynamic Programming approach for the UC problem. Table (4) summarizes such results from the main classical approach.

\subsection{Unit Commitment Solution by Particle Swarm Optimization}

Table (5) shows the results obtained using the PSO approach. From this results, it is clear that the PSO technique found the same results of Dynamic Programming approach. The schedule of the generation units was successfully established. The results showed also that PSO guarantee a global solution while deterministic optimization technique such as DP do not guarantee a global solution.

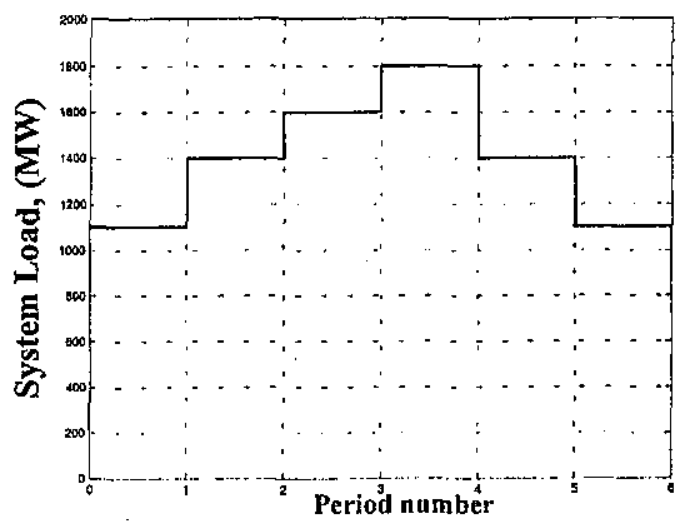

Fig. 1 System load demand

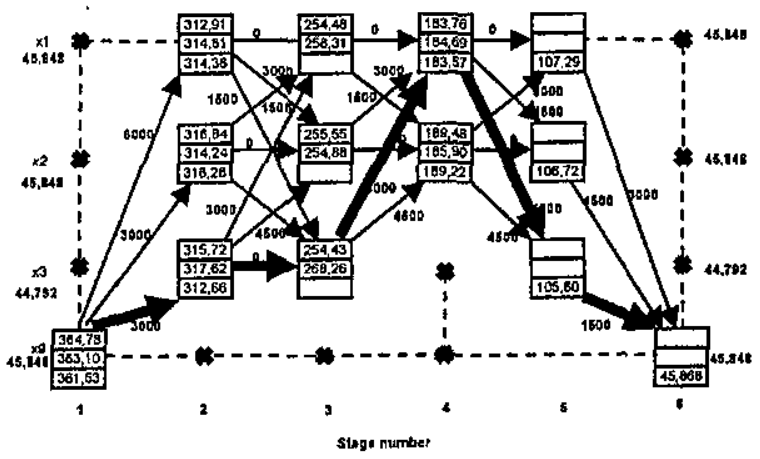

Fig. 2 Dynamic programming solution of the unit commitment problem.

Table 2. Generation Unit Data for UC Prablem

\begin{tabular}{|c|c|c|c|c|c|}
\hline \multirow{2}{*}{ Unit } & \multicolumn{2}{|c|}{$\begin{array}{c}\text { Generation } \\
\text { limits }\end{array}$} & \multicolumn{2}{c|}{ Fuel cost parameters } \\
\cline { 2 - 6 } & $\begin{array}{c}\text { Min. } \\
\text { Limit }\end{array}$ & $\begin{array}{c}\text { Max. } \\
\text { Limit }\end{array}$ & $c_{0}$ & $c_{1}$ & $c_{2}$ \\
\hline 1 & 100 & 625 & 0.004 & 8 & 500 \\
\hline 2 & 100 & 625 & 0.0048 & 6.4 & 400 \\
\hline 3 & 75 & 600 & 0.005 & 7.9 & 600 \\
\hline 4 & 75 & 500 & 0.0055 & 7.5 & 400 \\
\hline
\end{tabular}


Table 3 Economic Dispatch Results from the Main Classical Dynamic Programming Approach for the UC Problem

\begin{tabular}{|c|c|c|c|c|c|c|c|c|c|}
\hline $\begin{array}{l}\text { Combinations } \\
\mathrm{U}_{1} \mathrm{U}_{2} \mathrm{U}_{3} \mathrm{U}_{4}\end{array}$ & $\mathrm{P}_{\mathrm{Gl}}$ & $P_{G 2}$ & $\mathrm{P}_{\mathrm{G} 3}$ & $\mathrm{P}_{\mathrm{G} 4}$ & $F_{1}$ & $\mathrm{~F}_{2}$ & $\mathrm{~F}_{3}$ & $F_{4}$ & $\begin{array}{l}\text { Total production costs } \\
\text { (\$/period) }\end{array}$ \\
\hline \multicolumn{10}{|l|}{$\frac{\mathrm{U}_{1} \mathrm{U}_{2} \mathrm{U}_{3} \mathrm{U}_{4}}{\mathrm{Load}}=1100 \mathrm{MW}$} \\
\hline 1111 & 261 & 284 & 219 & 235 & 2861 & 3565 & 2570 & 2466 & 45,848 \\
\hline 1110 & 351 & 459 & 290 & 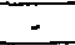 & 3801 & 4349 & 3312 & - & 45,848 \\
\hline 1101 & 347 & 456 & - & 298 & 3758 & 4317 & - & 3123 & 44,792 \\
\hline 1100 & 509 & 591 & $\because$ & - & 5608 & 5859 & - & - & 45,868 \\
\hline \multicolumn{10}{|l|}{ Load $=1400 \mathrm{MW}$} \\
\hline 1111 & 351 & 459 & 290 & 300 & 3801 & 4349 & 3312 & 3145 & 58,428 \\
\hline 1110 & 464 & 554 & 382 & 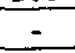 & 5073 & 5419 & 4347 & - & 59,356 \\
\hline 11001 & 464 & 553 & - & 383 & 5073 & 5407 & - & 4079 & 58,236 \\
\hline 1100 & \multicolumn{9}{|c|}{ Infeasible combination, load demand not met } \\
\hline \multicolumn{10}{|l|}{ Load $=1600 \mathrm{MW}$} \\
\hline 1111 & 410 & 508 & 338 & 344 & 4452 & 4894 & 3841 & 3145 & 67,258 \\
\hline 1110 & 541 & 617 & 442 & $\because$ & 5999 & 6176 & 5069 & - & 68,976 \\
\hline 1101 & 542 & 618 & - & 440 & 6011 & 6188 & - & 4079 & 67,856 \\
\hline 1100 & \multicolumn{9}{|c|}{ Infeasible combination, load demand not met } \\
\hline \multicolumn{10}{|l|}{$\mathrm{Load}=1800 \mathrm{MW}$} \\
\hline 1111 & 469 & 558 & 386 & 387 & 5132 & 5466 & 4394 & 4126 & 76,472 \\
\hline 1110 & 625 & 625 & 550 & . & 7063 & 6275 & 6458 & $=$ & 79,184 \\
\hline 1101 & \multirow{2}{*}{\multicolumn{9}{|c|}{$\begin{array}{l}\text { Infeasible combination, load demand not met } \\
\text { Infeasible combination, load demand not met }\end{array}$}} \\
\hline 1100 & & & & & & & & & \\
\hline
\end{tabular}

Table 4 Results from the Main Classical Approach for the UC Problem

\begin{tabular}{|c|c|c|c|c|}
\hline $\begin{array}{l}\text { Combinations } \\
\mathrm{U}_{1} \mathrm{U}_{2} \mathrm{U}_{3} \mathrm{U}_{4}\end{array}$ & $P_{G 1}$ & $P_{\mathrm{G} 2}$ & $P_{\mathrm{G} 3}$ & $P_{G 4}$ \\
\hline \multicolumn{5}{|c|}{$\mathrm{Load}=1100 \mathrm{MW}$} \\
\hline 1100 & 509 & 591 & - & - \\
\hline \multicolumn{5}{|c|}{ Load $=1400 \mathrm{MW}$} \\
\hline 1101 & $\overline{464}$ & 553 & - & 383 \\
\hline \multicolumn{5}{|c|}{ Load $=1600 \mathrm{MW}$} \\
\hline 1111 & 410 & 508 & 338 & 344 \\
\hline \multicolumn{5}{|c|}{ Load $=1600 \mathrm{MW}$} \\
\hline 11111 & 469 & 558 & 386 & 387 \\
\hline \multicolumn{5}{|c|}{ Load $=1400 \mathrm{MW}$} \\
\hline 1101 & 464 & 553 & - & 383 \\
\hline \multicolumn{5}{|c|}{ Load $=1100 \mathrm{MW}$} \\
\hline 1100 & 509 & 591 & - & - \\
\hline \multicolumn{5}{|c|}{ Overall generation costs $=\$ 360,946$} \\
\hline
\end{tabular}

Table 5 Results from the PSO technique for the UC Problem

\begin{tabular}{|c|c|c|c|c|}
\hline $\begin{array}{c}\text { Combinations } \\
U_{1} U_{2} U_{3} U_{4}\end{array}$ & $\mathrm{P}_{\mathrm{G} 1}$ & $\mathrm{P}_{\mathrm{G} 2}$ & $\mathrm{P}_{\mathrm{G} 3}$ & $\mathrm{P}_{\mathrm{G} 4}$ \\
\hline \multicolumn{5}{|l|}{ Load $=1100 \mathrm{MW}$} \\
\hline 1100 & 509.1 & 590.9 & - & - \\
\hline \multicolumn{5}{|c|}{ Load $=1400 \mathrm{MW}$} \\
\hline 1101 & 463.9 & 553.3 & こ & $382: 8$ \\
\hline \multicolumn{5}{|l|}{ Load $=1600 \mathrm{MW}$} \\
\hline 1111 & 410.0 & 508.3 & 338.0 & 343.6 \\
\hline \multicolumn{5}{|l|}{ Load $=1600 \mathrm{MW}$} \\
\hline 1111 & 469 & 558 & 385.6 & 386.9 \\
\hline \multicolumn{5}{|l|}{ Load $=1400 \mathrm{MW}$} \\
\hline 1101 & 463.9 & 553.3 & - & 382.8 \\
\hline \multicolumn{5}{|l|}{ Load $=1100 \mathrm{MW}$} \\
\hline 1100 & 509.1 & 590.9 & - & - \\
\hline Over & & sts $=s$ & 19 & \\
\hline
\end{tabular}

Note that only generation units 1 and 2 are to operate at the first and final periods of the load cycle.

\section{CONCLUSIONS}

In this paper, the solution methodology of the unit commitment problem based on PSO technique was developed. The results obtained using PSO technique were compared with those obtained by classical Dynamic Programming technique. This comparison shows that: the proposed PSO technique guarantees a global solution to the unit commitment problem while the dynamic programming approach is a deterministic optimization technique, and does not guarantee a global solution to the problem.

\section{REFERENCES}

[1] Berna Dengiz, Fulya Altiparmak and Alice E. Smith, "Local Search Genetic Algorithm for Optimal Design of Reliable Netpapers", IEEE Transactions on Evolutionary Computation, Vol. 1, No. 3, Sep. 1997, pp.179-188.

[2] Hans-Georg Beyer and Hans-Paul Schwefel, "Evolution Strategies, a Comprehensive Introduction", Natural Computing: an International Journal, Volume 1, Issue 1, May 2002, pp. 3-52.

[3] P.J.M. van Laarhoven and E.H.L. Aarts, "Simulated Annealing: Theory and Applications", D. Reidel Publishing Company, Kluwer, 1987. 
[4] Hu X H, Eberhart R C, Shi Y H. Engineering optimization with particle swarm. IEEE Swarm Intelligence Symposium, 2003, pp. 53-57.

[5] J. Kennedy and R. Eberhart, "Particle Swarm Optimization", Proceedings of the 1995 IEEE International Conference on Neural Networks, pp. 1942-1948.

[6] Kalyan Veeramachaneni, Thanmaya Peram, Chilukuri Mohan, Lisa Ann Osadciw, "Optimization Using Particle Swarm with Near Neighbor Interactions", Genetic and Evolutionary Computation Conference, July 12$17^{\text {th }}$, Chicago, llinois, 2003.

[7] Pang, C. K. and Chen, H. C., "Optimal ShortTerm Thermal Unit Commitment", IEEE transactions on Power Apparatus and Systems, Vol. PAS-95, No. 4, 1976, pp.1336-1342.

[8] M. H. Sendaula; S. K. Biswas, A. Eltom, C. Parten and W. Kazibwe, "Application of Artificial Neural Netpapers to Unit Commitment", Proceedings of the First International Neural Netpapers to Power Systems, 23-26 July 1991, pp. 256-260.

[9] P. O. Lindberg and T. Magnusson, "The Unit Commitment Problem: A Dual Approach", Proceedings of the $28^{\text {th }}$ IEEE Conference on Decision and Control, Vol. 2, Dec. 13-15, 1989 pp. 1127-1130.

[10] H. Kun-Yuan; Y. Hong-Tzer and H. ChingLien, "A New Thermal Unit Commitment

Approach Using Constraint Logic Programming", IEEE Transaction on Power Systems, Vol. 13, Issue 3, August 1998, pp. 936-945.

[11] M. Madrigal and V. H. Quintana, "An InteriorPoint/Cutting-Plane Method to Solve Unit Commitment Problems", IEEE Transaction on Power Systems, Vol. 15, Issue 3, August 2000, pp. 1022-1027.

[12] S. Takriti and J. R. Birge, "Using Integer Programming to Refine Lagrangian-Based Unit Commitment Solutions", IEEE Transaction on
Power Systems, Vol. 15, Issue 1, February 2000, pp. 151-156.

[13] Li Chao-An, R. B. Johnson and A. J. Svoboda "A New Unit Commitment Method", IEEE Transaction on Power Systems, Vol. 12, Issue 1, Feb. 1997, pp. 113-119.

[14] H. Mantawy, Y. L. Abdel-Magid and S. Z. Selim, "Integrating Genetic Algorithms, Tabu Search, and Simulated Annealing for the Unit Commitment Problem", IEEE Transaction on Power Systems, Vol. 14, Issue 3, August 1999, pp. 829-836.

[15] D. Dasgupta and D. R. McGregor, "Thermal Unit .Commitment Using Genetic Algorithms", IEE Proceedings - Generation, Transmission and Distribution, Vol. 141, Issue 5, September 1994, pp. 459-465.

[16] S. Mokhtari; J. Sing and B. Wollenberg, "A Unit Commitment Expert System", IEEE Transaction on Power Systems, Vol. 3, Issue 1, February 1988, pp. 272-277.

[17] J. J. Grainger and W. D. Stevenson Jr., "Power System Analysis", McGraw-Hill Electrical and Computer Engineering Series, 1994.

[18] J. Kennedy and R. Eberhart, "Particle Swarm Optimization", Proceedings of the 1995 IEEE International Conference on Neural Netpapers, pp. 1942-1948.

[19] F. Heppner and U. Grenander, "A Stochastic Nonlinear Model for Coordinated Bird Flocks", The Ubiquity of Chaos, AAAS Publications, Washington DC, 1990.

[20] Mendes, R., Kennedy, J., and Neves, J., "Watch thy neighbor or how the swarm can learn from its environment", The Iberoamerican Conference on Artificial Intelligence (IBERAMIA), Seville, November 2002.

[21] Y. Shi and R. Eberhart, "A Modified Particle Optimizer", Proceedings of the 1998 IEEE World Congress on Computational intelligence, May 1998, pp. 69-73. 